\title{
Current Status of Photodynamic Therapy in Digestive Tract Carcinoma in Japan
}

\author{
Atsushi Nanashima $^{\dagger, *}$ and Takeshi Nagayasu ${ }^{\dagger}$ \\ Department of Surgical Oncology, Nagasaki University Graduate School of Biomedical Sciences, \\ 1-7-1, Sakamoto, Nagasaki 852-8501, Japan; E-Mail: nagayasu@nagasaki-u.ac.jp \\ $\dagger$ These authors contributed equally to this work. \\ * Author to whom correspondence should be addressed; E-Mail: ananasm7@gmail.com; \\ Tel.: +81-95-819-7304; Fax: +81-95-819-7306.
}

Academic Editor: Michael R. Hamblin

Received: 15 December 2014 / Accepted: 30 January 2015 / Published: 4 February 2015

\begin{abstract}
Photodynamic therapy (PDT) is an effective local treatment modality as a cancer-specific laser ablation in malignancy of some organs including digestive tracts or bile duct. In Japan, PDT has been applied at the early period after the first clinical induction in 1980's. Although the useful efficacy was clarified, PDT has not been fully applied because of the phototoxicity of the porfimer sodium. The next generated talaporfin-sodium was used for PDT, in which phototoxicity was reduced and, however, the clinical efficacy for digestive tract malignancy has not yet been clarified. By proceeding the experimental and clinical trials, it is necessary to clarify the evidence of efficacy as a local powerful treatment with the conventional surgery, brachiotherapy and chemotherapy in the future step.
\end{abstract}

Keywords: photodynamic therapy; digestive tract cancer; bile duct carcinoma; porfimer sodium; talaporfin sodium; Japan 


\section{Introduction}

\section{Induction of Photodynamic Therapy for Digestive Tract Carcinoma in Japan}

Photodynamic therapy (PDT) has been clinically applied for human carcinomas by Dougherty et al. [1] since 1978. Since the 1990s, there have been many advances of PDT in the treatment of digestive tract carcinomas, such as in the esophagus, stomach, and bile duct, in Japanese series [2-8]. In these series, PDT using $2 \mathrm{mg}$ per kg body weight of porfimer sodium (Photofrin ${ }^{\circledR}$; Wyeth-Takeda, Tokyo, Japan) was used as a photosensitizer. After administration, patients avoided direct sunlight for 4-6 weeks. The excitation light source used was an Excimer dye laser (PDT-EDL1: Hamamatsu Photonics K.K., Hamamatsu, Japan). The wavelength was $630 \mathrm{~nm}$, irradiation output was $4 \mathrm{~mJ} / \mathrm{pulse} / \mathrm{cm}^{2}$, and the frequency was $40 \mathrm{~Hz}$. Irradiation was performed with the free cut or cylindrical type of laser fiber placed approximately $1 \mathrm{~cm}$ from the lesion to make an irradiation spot of $1 \mathrm{~cm}^{2}$ at $48-72 \mathrm{~h}$ after photosensitizer administration. Light doses consisted of $100 \mathrm{~J} / \mathrm{cm}^{2}$. By the above investigators' efforts, PDT has been approved as a radical treatment in the digestive tract for superficial carcinoma of the esophagus and stomach under the national health insurance system by the Ministry of Health and Welfare, Japan, since 1994.

\section{Results and Discussion}

\subsection{Photodynamic Therapy (PDT) for Esophageal and Gastric Carcinoma}

PDT using porfimer sodium (P-PDT) was shown to be an effective and radical treatment option for superficial esophageal and gastric adenocarcinoma; however, the use of this modality has not spread clinically because of the need for long-term shielding from light and an expensive laser apparatus. Endoscopic mucosal resection (EMR) and endoscopic submucosal dissection (ESD) were developed for minimally invasive, organ-sparing endoscopic removal of early malignant lesions in the gastrointestinal tract worldwide, including in Japan, during the same period [9-11]. In the case of a contra-indication for EMR or ESD, argon plasma coagulation could also be applied at a lower cost than P-PDT [12]. Therefore, the P-PDT option is currently excluded from the Japanese guidelines for the treatment of gastric cancer and P-PDT has only been performed at limited Japanese institutions.

\subsection{PDT for Bile Duct Carcinoma}

With respect to other digestive tract carcinomas, P-PDT was clinically applied for unresectable bile duct carcinomas worldwide, including in Japan. Between 1998 and 2006, European cancer institutes showed the improved patient status and survival benefits of P-PDT for unresectable bile duct carcinomas by randomized or phase II prospective trials [13-18]. The most recent articles on PDT for unresectable BDC indicated improvement in liver function, patient quality of life, and prolongation of the survival period, with few complications [19]. Thus, PDT also appears to be a promising modality for local treatment in BDC. A few Japanese institutes have shown the effectiveness of P-PDT via case reports and a retrospective study reported in English [5]. P-PDT was also described as being effective for prolonging the survival period in resected bile duct carcinoma in German reports [20,21]. Our report also showed the effect of P-PDT for the local control of bile duct carcinoma in unresectable 
cases and resected cases with remnant microscopic cancer cells at the bile duct stump [22]. At our institute, departments of digestive medicine, digestive and thoracic surgery, oral surgery, gynecology, dermatology, and brain surgery have attempted PDT in each field of cancer treatments; thus, Nagasaki conferences specializing in PDT have been held since 2004. Unfortunately, the maintenance service of PDT-EDL1 was discontinued by the company in 2012 and the use of P-PDT has gradually come to an end in Japan.

\subsection{New Application of PDT Using Talaporfin Sodium}

In 2009, PDT using a new photosensitizer, talaporfin sodium (Chemical Formula: C38H37N5Na4O9) (mono-L-aspartyl chlorin e6 [NPe6], Laserphyrin ${ }^{\circledR}$; Meiji Seika Pharma Co., Ltd., Tokyo, Japan) was started for superficial carcinoma of the respiratory tract under the Japanese health insurance system [23]. Semiconductor laser light (Panasonic Healthcare Co., Ltd., Tokyo, Japan) of 664 nm was used for laser activation. PDT using talaporfin sodium (T-PDT) showed lower skin phototoxicity than P-PDT, so the period of light shielding could be shortened to within 2 weeks. Nakamura et al. [24] performed T-PDT and its photodynamic diagnosis for treatment in superficially infiltrated gastric cancer. T-PDT was also applied for local failure after chemoradiotherapy or radiotherapy for patients with esophageal cancer as a phase I prospective study by Yano et al. [25]. At present, a multi-institute phase III trial for esophageal carcinomas is underway in Japan (unpublished). Our group also started a phase I/II clinical trial of T-PDT for patients with unresectable bile duct carcinoma and resected cases with remnant cancer cells of bile duct carcinoma at the bile duct stump in 2009 [26]. At present, it is considered that T-PDT could be safely achieved, but its survival benefit remains unknown. PDT was recommended in the first edition of the Japanese guidelines of treatment for bile duct carcinoma in 2007; however, this recommendation was canceled in the second edition in 2014 [27].

\subsection{Endoscopic Access of Laser Radiation for PDT}

For esophageal, stomach, and intestinal carcinomas, an endoscopic approach of PDT is not difficult, but endoscopy-guided laser radiation via the bile duct is relatively difficult. The following approaches for endoscopy routes are considered: (1) the percutaneous transhepatic biliary; (2) the percutaneous transjejunal route after surgery; and (3) the endoscopic retrograde biliary route via the duodenal papilla [28]. Rumalla et al. [29,30] reported a route for endoscopic retrograde cholangiography using the railway method. However, the development of more precise techniques for approaching bile duct carcinoma is necessary.

\section{Experimental Section}

\subsection{PDT Using Talaporfin Sodium}

Some investigators also showed good cancer cell toxicity in digestive tract carcinomas in an animal model [31,32]. Kasuya et al. [33,34] and our group also showed the increased apoptotic effects of T-PDT in a bile duct cancer cell line in vivo in comparison with that of P-PDT. Comparison between chemotherapy alone and PDT is expected as future work. Our basic study showed increased activity by the combination of PDT and an anti-cancer drug, such as gemcitabine or oxaliplatin [35]. 


\subsection{PDT Using a New Photosensitizer}

Tanaka et al. [36,37] attempted to apply PDT with the third-generation photosensitizer, glucose-conjugated chlorine (H2TFPC-SGlc), for gastric and colon carcinoma or gastrointestinal stromal tumor of the stomach in a rat model, with a specific wavelength of a semi-conductor laser. Hayashi et al. [38] also showed the efficacy of mannose-conjugated chlorin PDT in gastric cancer as well. Our group also examined this new agent for PDT in bile duct carcinoma in vitro and in vivo (unpublished). The development of a photosensitizer and a low-cost laser apparatus should be expected to accomplish PDT as a conventional anti-cancer therapy in digestive tract carcinoma.

\section{Conclusions}

Although PDT is a cancer-specific and safe treatment option for digestive tract carcinomas, its clinical application has been limited worldwide, as well as in Japan. How do we move forward? Specifically, there is a need for studies regarding (1) a new photosensitizer with a more effective cytocidal effect, lower phototoxicity, and a shortened period of light shielding; (2) a portable laser apparatus with deeper penetration of tissue and lower cost; and (3) the technical development of an endoscopic approach as a future step to acquire a consensus on the conventional treatment approved by the Japanese national health insurance system.

\section{Author Contributions}

All experimental and clinical works.

\section{Conflicts of Interest}

The authors declare no conflict of interest.

\section{References}

1. Dougherty, T.J.; Kaufman, J.E.; Goldfarb, A.; Weishaupt, K.R.; Boyle, D.; Mittleman, A. Photoradiation therapy for the treatment of malignant tumors. Cancer Res. 1978, 38, 2628-2635.

2. Kato, H. History of photodynamic therapy_ past, present and future (in Japanese). Gan Kagaku Ryoho 1996, 23, 8-15.

3. Okunaka, T.; Kato, H.; Conaka, C.; Yamamoto, H.; Bonaminio, A.; Eckhauser, M.L. Photodynamic therapy of esophageal carcinoma. Surg. Endosc. 1990, 4, 150-153.

4. Mimura, S.; Ito, Y.; Nagayo, T.; Ichii, M.; Kato, H.; Sakai H.; Goto, K.; Noguchi, Y.; Tanimura, H.; Nagai, Y.; et al. Cooperative clinical trial of photodynamic therapy with photofrin II and excimer dye laser for early gastric cancer. Lasers Surg. Med. 1996, 19, 168-172.

5. Suzuki, S.; Inaba, K.; Yokoi, Y.; Ohata, K.; Ota, S.; Azuma, M.; Tanaka, T.; Konno, H.; Baba, S.; Hirano, T.; et al. Photodynamic therapy for malignant biliary obstruction: A case series. Endoscopy 2004, 36, 83-87. 
6. Yano, T.; Muto, M.; Minashi, K.; Ohtsu, A.; Yoshida, S. Photodynamic therapy as salvage treatment for local failures after definitive chemoradiotherapy for esophageal cancer. Gastrointest. Endosc. 2005, 62, 31-36.

7. Tanaka, T.; Matono, S.; Nagano, T.; Murata, K.; Sueyoshi, S.; Yamana, H.; Shirouzu, K.; Fujita, H. Photodynamic therapy for large superficial squamous cell carcinoma of the esophagus. Gastrointest. Endosc. 2011, 73, 1-6.

8. Yano, T.; Muto, M.; Minashi, K.; Iwasaki, J.; Kojima, T.; Fuse, N.; Doi, T.; Kaneko, K.; Ohtsu, A. Photodynamic therapy as salvage treatment for local failure after chemoradiotherapy in patients with esophageal squamous cell carcinoma: A phase II study. Int. J. Cancer 2012, 131, 1228-1234.

9. Kakushima, N.; Fujishiro, M. Endoscopic submucosal dissection for gastrointestinal neoplasms. World J. Gastroenterol. 2008, 14, 2962-2967.

10. Shimizu, Y.; Takahashi, M.; Yoshida, T.; Ono, S.; Mabe, K.; Kato, M.; Asaka, M.; Sakamoto, N. Endoscopic resection (endoscopic mucosal resection/endoscopic submucosal dissection) for superficial esophageal squamous cell carcinoma: current status of various techniques. Dig. Endosc. 2013, 25, 13-19.

11. Gotoda, T.; Kusano, C.; Moriyasu, F. Future perspective of gastric cancer endotherapy. Ann. Transl. Med. 2014, 2, doi:10.3978/j.issn.2305-5839.2014.03.03.

12. Tomita, T.; Arai, E.; Kohno, T.; Kondo, T.; Kim, Y.; Oshima, T.; Hori, K.; Watari, J.; Matsumoto, T.; Miwa, H. Outcomes of treatment of argon plasma coagulation therapy in elderly or high-risk patients with early gastric cancer: A comparison of outcomes among experienced and nonexperienced endoscopists. J. Clin. Gastroenterol. 2011, 45, e54-e59.

13. Ortner, M.A.; Liebetruth, J.; Schreiber, S.; Hanft, M.; Wruck, U.; Fusco, V.; Müller, J.M.; Hörtnagl, H.; Lochs, H. Photodynamic therapy of nonresectable cholangiocarcinoma. Gastroenterology 1998, 114, 536-542.

14. Berr, F.; Wiedmann, M.; Tannapfel, A.; Halm, U.; Kohlhaw, K.R.; Schmidt, F.; Wittekind, C.; Hauss, J.; Mössner, J. Photodynamic therapy for advanced bile duct cancer: Evidence for improved palliation and extended survival. Hepatology 2000, 31, 291-298.

15. Dumoulin, F.L.; Gerhardt, T.; Fuchs, S.; Scheurlen, C.; Neubrand, M.; Layer, G.; Sauerbruch, T. Phase II study of photodynamic therapy and metal stent as palliative treatment for nonresectable hilar cholangiocarcinoma. Gastrointest. Endosc. 2003, 57, 860-867.

16. Wiedmann, M.; Berr, F.; Schiefke, I.; Witzigmann, H.; Kohlhaw, K.; Mössner, J.; Caca, K. Photodynamic therapy in patients with non-resectable hilar cholangiocarcinoma: 5-Year follow-up of a prospective phase II study. Gastrointest. Endosc. 2004, 60, 68-75.

17. Zoepf, T.; Jakobs, R.; Arnold, J.C.; Apel, D.; Riemann, J.F. Palliation of nonresectable bile duct cancer: Improved survival after photodynamic therapy. Am. J. Gastroenterol. 2005, 100, 2426-2430.

18. Witzigmann, H.; Berr, F.; Ringel, U.; Caca, K.; Uhlmann, D.; Schoppmeyer, K.; Tannapfel, A.; Wittekind, C.; Mossner, J.; Hauss, J.; et al. Surgical and palliative management and outcome in 184 patients with hilar cholangiocarcinoma: Palliative photodynamic therapy plus stenting is comparable to $\mathrm{r} 1 / \mathrm{r} 2$ resection. Ann. Surg. 2006, 244, 230-239.

19. Tomizawa, Y.; Tian, J. Photodynamic therapy for unresectable cholangiocarcinoma. Dig. Dis. Sci. 2012, 57, 274-283. 
20. Berr, F.; Tannapfel, A.; Lamesch, P.; Pahernik, S.; Wiedmann, M.; Halm, U.; Goetz, A.E.; Mössner, J.; Hauss, J. Neoadjuvant photodynamic therapy before curative resection of proximal bile duct carcinoma. J. Hepatol. 2000, 32, 352-357.

21. Wiedmann, M.; Caca, K.; Berr, F.; Schiefke, I.; Tannapfel, A.; Wittekind, C.; Mössner, J.; Hauss, J.; Witzigmann, H. Neoadjuvant photodynamic therapy as a new approach to treating hilar cholangiocarcinoma: A phase II pilot study. Cancer 2003, 97, 2783-2790.

22. Nanashima, A.; Yamaguchi, H.; Ide, N.; Shibasaki, S.; Sawai, T.; Tsuji, T.; Hidaka, S.; Sumida, Y.; Nakagoe, T.; Nagayasu T. Adjuvant photodynamic therapy for bile duct carcinoma after surgery: A preliminary study. J. Gastroenterol. 2004, 39, 1095-1101.

23. Usuda, J.; Tsutsui, H.; Honda, H.; Ichinose, S.; Ishizumi, T.; Hirata, T.; Inoue, T.; Ohtani, K.; Maehara, S.; Imai, K.; et al. Photodynamic therapy for lung cancers based on novel photodynamic diagnosis using talaporfin sodium (NPe6) and autofluorescence bronchoscopy. Lung Cancer 2007, 58, 317-323.

24. Nakamura, T.; Oinuma, T. Usefulness of photodynamic diagnosis and therapy using talaporfin sodium for an advanced-aged patient with inoperable gastric cancer (a secondary publication). Laser Ther. 2014, 23, 201-210

25. Yano, T.; Muto, M.; Yoshimura, K.; Niimi, M.; Ezoe, Y.; Yoda, Y.; Yamamoto, Y.; Nishisaki, H.; Higashino, K.; Ishii, H. Phase I study of photodynamic therapy using talaporfin sodium and diode laser for local failure after chemoradiotherapy for esophageal cancer. Radiat. Oncol. 2012, 7 , doi:10.1186/1748-717X-7-113.

26. Nanashima, A.; Abo, T.; Nonaka, T.; Nonaka, Y.; Morisaki, T.; Uehara, R.; Ohnita, K.; Fukuda, D.; Murakami, G.; Tou, K.; et al. Photodynamic therapy using talaporfin sodium $\left(\right.$ Laserphyrin $^{\circledR}$ ) for bile duct carcinoma: A preliminary clinical trial. Anticancer Res. 2012, 32, 4931-4938.

27. Saito, H.; Takada, T.; Miyazaki, M.; Miyakawa, S.; Tsukada, K.; Nagino, M.; Kondo, S.; Furuse, J.; Tsuyuguchi, T.; Kimura, F.; et al. Radiation therapy and photodynamic therapy for biliary tract and ampullary carcinomas. J. Hepatobiliary Pancreat. Surg. 2008, 15, 63-68.

28. Nanashima, A.; Isomoto, H.; Abo, T.; Nonaka, T.; Morisaki, T.; Arai, J.; Takagi, K.; Ohnita, K.; Shoji, H.; Urabe, S.; et al. How to access photodynamic therapy for bile duct carcinoma. Ann. Transl. Med. 2014, 2, 23-26.

29. Rumalla, A.; Baron, T.H.; Wang, K.K.; Gores, G.J.; Stadheim, L.M.; de Groen, P.C. Endoscopic application of photodynamic therapy for cholangiocarcinoma. Gastrointest. Endosc. 2001, 53, 500-504.

30. Harewood, G.C.; Baron, T.H.; Rumalla, A.; Wang, K.K.; Gores, G.J.; Stadheim, L.M.; de Groen, P.C. Pilot study to assess patient outcomes following endoscopic application of photodynamic therapy for advanced cholangiocarcinoma. J. Gastroenterol. Hepatol. 2005, 20, 415-420.

31. Kishi, K.; Yano, M.; Inoue, M.; Miyashiro, I.; Motoori, M.; Tanaka, K.; Goto, K.; Eguchi, H.; Noura, S.; Yamada, T.; et al. Talaporfin-mediated photodynamic therapy for peritoneal metastasis of gastric cancer in an in vivo mouse model: drug distribution and efficacy studies. Int. J. Oncol. 2010, 36, 313-320. 
32. Harvey, E.H.; Webber, J.; Kessel, D.; Fromm, D. Killing tumor cells: the effect of photodynamic therapy using mono-L-aspartyl chlorine and NS-398. Am. J. Surg. 2005, 189, 302-305.

33. Kasuya, K.; Shimazu, M.; Suzuki, M.; Kuroiwa, Y.; Usuda, J.; Itoi, T.; Tsuchida, A.; Aoki, T. Novel photodynamic therapy against biliary tract carcinoma using mono-L-aspartyl chlorine e6: Basic evaluation for its feasibility and efficacy. J. Hepatobiliary Pancreat. Sci. 2010, 17, 313-321.

34. Nonaka, T.; Nanashima, A.; Nonaka, M.; Uehara, M.; Isomoto, H.; Nonaka, Y.; Nagayasu, T. Advantages of laserphyrin compared with photofrin in photodynamic therapy for bile duct carcinoma. J. Hepatobiliary Pancreat. Sci. 2011, 18, 592-600.

35. Nonaka, Y.; Nanashima, A.; Nonaka, T.; Uehara, M.; Isomoto, H.; Abo, T.; Nagayasu, T. Synergic effect of photodynamic therapy using talaporfin sodium with conventional anticancer chemotherapy for the treatment of bile duct carcinoma. J. Surg. Res. 2013, 181, 234-241.

36. Tanaka, M.; Kataoka, H.; Yano, S.; Ohi, H.; Moriwaki, K.; Akashi, H.; Taguchi, T.; Hayashi, N.; Hamano, S.; Mori, Y.; et al. Antitumor effects in gastrointestinal stromal tumors using photodynamic therapy with a novel glucose-conjugated chlorin. Mol. Cancer Ther. 2014, 13, doi:10.1158/1535-7163.MCT-13-0393

37. Tanaka, M.; Kataoka, H.; Mabuchi, M.; Sakuma, S.; Takahashi, S.; Tujii, R.; Akashi, H.; Ohi, H.; Yano, S.; Morita, A.; et al. Anticancer effects of novel photodynamic therapy with glycoconjugated chlorin for gastric and colon cancer. Anticancer Res. 2011, 31, 763-769.

38. Hayashi, N.; Kataoka, H.; Yano, S.; Tanaka, M.; Moriwaki, K.; Akashi, H.; Suzuki, S.; Mori, Y.; Kubota, E.; Tanida, S.; et al. A novel photodynamic therapy targeting cancer cells and tumor-associated macrophages. Mol. Cancer Ther. 2014, doi:10.1158/1535-7163.MCT-14-0348.

(C) 2015 by the authors; licensee MDPI, Basel, Switzerland. This article is an open access article distributed under the terms and conditions of the Creative Commons Attribution license (http://creativecommons.org/licenses/by/4.0/). 